\title{
MEME KANSERİ TANISI İÇİN DERİN ÖZNİTELIKK TABANLI KARAR DESTEK SİSTEMİ
}

\author{
${ }^{1}$ Nuh ALPASLAN \\ ${ }^{1 B i n g o ̈ l ~ U ̈ n i v e r s i t e s i, ~ M u ̈ h e n d i s l i k-M i m a r l k ~ F a k u ̈ l t e s i, ~ B i l g i s a y a r ~ M u ̈ h e n d i s l i g ̆ i ~ B o ̈ l u ̈ m u ̈, ~ B I ̇ N G O ̈ L ~}$ \\ ${ }^{1}$ nalpaslan@bingol.edu.tr
}

(Geliş/Received: 19.04.2018; Kabul/Accepted in Revised Form: 24.10.2018)

\begin{abstract}
ÖZET: Meme kanseri, akciğer kanserinden sonra kadınlarda kanser ölümlerinin ikinci önemli sebebidir. Erken tanı, meme kanseri tedavisinde oldukça önemlidir. Mamografi, meme kanserinin erken teşhisinde en çok kullanılan görüntüleme tekniğidir. Yapılan araştırmalar, 50 yaşın üstünde düzenli mamografi çektirmenin kadınlar için ölüm oranını \%30 oranında azaltabileceğini göstermektedir. Ancak, mamogramların yorumlanması genellikle özneldir. Bu çalışmada, göğüs kitlelerinin otomatik tespiti, sınıflandırılması ve içerik tabanlı erişimi için entegre bir sistem sunulmuştur. Bu kapsamda, hekimlerin kitle hakkındaki kararları, üst düzey derin öznitelikler ve düşük seviye öznitelik seti ile ifade edilmiştir. Önerilen sistemde düşük seviyeli öznitelikleri elde etmek için, kitle tespitinde graf tabanlı görsel çıkıntı yöntemi kullanılmış ve öznitelik çıkarımı için örneklemesiz contourlet dönüşümü ve eig(Hess)-HOG yöntemleri kullanılmıştır. Ayrıca, yüksek seviyeli evrişimsel sinir ağı öznitelikleri kullanılmıştır. Ardından, test görüntülerinin kategorisini tahmin etmek için yukarıda bahsedilen özniteliklere dayalı iki aşırı öğrenme makinesi (AÖM) sınıflandırıcısı kullanılmıştır. Farklı özniteliklere dayalı sınıflandırıcıların sonuçları, test görüntülerinin türünü belirlemek için analiz edilmiştir. Görüntü erişimi ve sınıflandırma performansları, hem kesinlik-duyarlılık hem de sinıflandırma doğrulukları kullanarak IRMA mammographic patches veri setinde değerlendirilip ve karşılaştırılmıştır. Deneysel sonuçlar, önerilen sistemin etkililiğini ve gerçek zamanlı klinik uygulamalardaki kullanılabilirliğini göstermektedir.
\end{abstract}

Anahtar Kelimeler: Meme Kanseri, Mamogram, Sınıflandırma, Bilgisayar Destekli Tanı, İçerik tabanlı görüntü erişimi

\section{A Deep Feature Based Decision Support System for Breast Cancer Diagnosis}

ABSTRACT: The breast cancer is the second leading cause of cancer deaths among women after lung cancer. Early diagnosis is quite significant with breast cancer treatment. Mammography is the most commonly used imaging technique for the early detection of breast cancer. Researches have been shown that the mortality rate can decrease by $30 \%$ for women who have mammogram regularly over 50 years of age (Jadoon et al. 2017). However, interpreting mammograms is often subjective.

In this study, an integrated system for automated detection, classification, and content based retrieval of breast masses is presented. In this manner, physician's decisions on mass were expressed by high-level deep features and low-level feature set. In proposed framework, to extract low-level features, a graph based visual saliency (GBVS) method is used for mass detection and the nonsubsampled contourlet transform (NSCT) and eig(Hess)-HOG are used for feature extraction. In addition, high-level convolutional neural network features have been used. Then, two extreme learning machine (ELM) classifiers rely on the features mentioned above is employed to predict category of test images. And outputs of classifiers based on each feature were examined together to define the kind of test image. The image retrieval and classification performances are evaluated and compared on IRMA mammographic dataset by using both the precision-recall (PR) and classification accuracies. Experimental results demonstrate the effectiveness of the proposed system and the viability of a real-time clinical application.

Key Words: Breast cancer, Mammogram, Classification, Computer-aided diagnosis (CAD), Content-based image retrieval 


\section{GİRIŞ (INTRODUCTION)}

Teknolojinin üstel büyümesi, hızla azalan depolama maliyeti ve sürekli artan internet erişimi ile son y1llarda sayısal bilgi miktarı katlanarak artmıştır. Dolayısıyla, veriden doğru ve ilgili bilgilere erişmek en önemli problemlerden biridir. İçerik tabanlı görüntü erişimi (İTGE), bilgisayar destekli tıbbi tanı sistemleri, sanat, askeri ve mimari gibi birçok uygulama alanında kullanılmaktadır ("American Cancer Society Published Second Edition of Global Cancer Atlas" 2015). Son yıllarda, tatminkâr İTGE sistemleri için talep büyük ölçüde artmıştır.

ITGE, görüntü içeriğinden otomatik olarak elde edilen özniteliklere dayalı olarak bir veri tabanından ilgili imgelere erişme işlemidir. İmge içeriğini ayrıntılı olarak ifade etmek için, hem veritabanı hem de sorgu görüntüleri için renk, doku, şekil öznitelikleri elde edilir. Bu elde edilen öznitelikler sorgu görüntüsüne en benzer görüntüleri belirlemek için kullanılır.

Meme kanseri, hem gelişmiş hem de gelişmekte olan ülkelerde akciğer kanserinden sonra kadınlarda kanser ölümlerinin önde gelen nedenlerinden biri olduğu için önemli bir sağlık sorunu olarak kabul edilmektedir ("American Cancer Society Published Second Edition of Global Cancer Atlas" 2015; AL Mousa et al. 2014; Tabár et al. 2011). ABD'de tüm kanser teşhislerinin üçte birini oluşturmakta ve kadınlar arasındaki en yaygın kanser türüdür. Araştırmalar, 50 yaşın üstünde mamografi çektiren kadınlar için ölüm oranının \%30 oranında azalabileceğini göstermiştir (Siegel, Miller, and Jemal 2015; Nelson 2009; Ganesan et al. 2013). Mamografi, memenin ayrıntılı yapısını izlemek amacıyla günümüzde kullanılan en uygun maliyetli görüntüleme tekniğidir. Genel bir mamografi muayenesinde her göğüsten iki CC (kranio-kaudal) ve iki MLO (mediolateral oblik) olmak üzere 4 farklı görüntü alınmaktadır. Ancak, mamografilerin yorumlanması eğitim ve tecrübeye dayanmakta, genellikle zor, hataya eğilimli ve özneldir (Rangayyan, Ayres, and Leo Desautels 2007). Kanserin başlangıç safhalarındaki belirtiler görünüş açısından çeşitlidir ve tecrübeli radyologlar için bile tanı koymak oldukça zordur (Moura and Guevara López 2013; Y. Zhang et al. 2011). Radyologlar tarafından biyopsiye gönderilen kanser vakalarının \% 60 ila \% 85'i daha sonra iyi huylu olarak bulunmuştur (Rangayyan, Ayres, and Leo Desautels 2007). Ayrica, uzmanların değerlendirmek zorunda oldukları mamografilerin toplam sayısı, halkın bilinçlendirilmesi ile oldukça yüksek rakamlara ulaşmıştır (Nishikawa 2007; Zheng 2009). Her tür göğüs kitlesi, komşu dokulardan farklı niteliklere sahiptir. Böylece, göğüs kitleleri komşu dokulardan ayırt edilebilir. Kitlenin dokusal ve morfolojik öznitelikleri sınıflandırma için kullanılabilir. Kitlenin şekil, kenar özellikleri meme kitlelerinin ayrılması için önemli ipuçları taşımaktadır. Örneğin, kötü huylu kitleler yayılma eğilimdeyken; iyi huylu olanlar tutarlıdır. Ayrıca, kötü huylu kitleler düzensiz şekilli iken ve iyi huylu olanlar düzenli şekillere sahiptir. Uzmanların mamografileri yorumlarken hatalı teşhisi önlemek amacıyla bilgisayar destekli tanı sistemleri önerilmiştir.

Meme kitlelerinin tespiti amacıyla hekime yardımcı olmak için çok sayıda yöntem önerilmiştir (Nishikawa 2007; Zheng 2009). (Jadoon et al. 2017)'de derin öğrenme tabanlı yeni bir sınıflandırma yöntemi önerilmiştir. Önerilen iki yöntem, CNN-DW ve CNN-CT olarak isimlendirilmiştir. Bununla birlikte, İTGE tabanlı bilgisayar destekli tanı sistemleri, test veri kümelerinin eksikliği nedeniyle halen geliştirme aşamasındadır ve İTGE sistemlerinin klinik uygulamalarda kullanılması hala mümkün değildir. Son yıllarda klinik merkezlerde alınan mamografi miktarındaki olağanüstü artışa bağlı olarak, büyük veri tabanlarındaki görüntülere teşhis amaçlı erişim için etkili araçlar ve tekniklere açık bir ihtiyaç vardır. Mamografi için İTGE ile ilgili ilk çalışmalar, Alto ve ark. (Alto 2007) tarafından yapılmıştır. Bu çalışmada, meme kitle görüntülerine içerik tabanlı erişim için doku, gradyan ve şekil özniteliklerinin kullanılmasını önerdiler. Kinoshita ve ark. (Kinoshita et al. 2007), São Paulo üniversitesi'nden aldıkları mamografi veri setindeki görüntülere içerik tabanlı erişim için meme yoğunluğunu kullanmışlardır. ElNaqa ve ark. (El-Naqa et al. 2004) algısal benzerlik tahmininde iki basamaklı bir hiyerarşik öğrenme ağında yapay sinir ağları ve destek vektör makinesi kullanmayı önermişlerdir. Bing Zhang'ın (Zheng 2009) çalışmalarında, mamografiler için İTGE tabanlı bilgisayar destekli tanı şemaları karşılaştırılmış ve performansları değerlendirilmiştir. İTGE tabanlı bilgisayar destekli tanı sistemlerinin klinik uygulamada kabul edilmeden önce çok fazla araştırma çalışmalarına ihtiyaç olduğu sonucuna varılmıştır.

Bu çalışmanın amacı, otomatik kitle tespiti, sınıflandırılması ve mamografilere içerik tabanlı erişim için yeni bir karar destek sistemi geliştirmektir. Bu çalışmada İTGE tabanlı bir sistem önerilmiştir. Bu amaçla düşük ve yüksek seviyeli olmak üzere 2 farklı öznitelik seti elde edilmiştir. Düşük seviyeli öznitelikler öznitelik seti I olarak adlandırılmıştır. Öznitelik seti I, eig(Hess)-HOG, örneklemesiz contourlet dönüşümü, 9 boyutlu şekil, 7 boyutlu 
kitle ve 6 boyutlu doku özniteliklerinden meydana gelmektedir (Liu and Tang 2014). Öznitelik seti II, derin özellik tabanlı özniteliklerden oluşmaktadır. Yüksek seviyeli öznitelikler, tam olarak bağlı (fc7) eğitimli model tabakasından elde edilmiştir. Ardından, bu öznitelik kümeleri 2 AÖM sınıflandırıcısını eğitmek için kullanılmıştır. Son olarak, bu iki sınıflandırıcıların sonuçları birleştirilmiştir. Bu çalışmanın katkıları aşağıdaki gibi ifade edilebilir. Öncelikle AÖM tabanlı İTGE sistemi önerilmiştir. Bu sayede, sistem başarısından ödün vermeden görüntü erişim süresi azaltılarak, görüntü erişim hassasiyeti ve sınıflandırma doğruluğu artırılmıştır. Deneysel sonuçlar, yaklaşımlarımızın teşhis doğruluğundaki verimliliğini göstermektedir. Bunun yanında, örneklemesiz contourlet dönüşümü mamogram görüntüleri için öznitelik çıkarma aşamasında ilk defa uygulanmıştır. Literatürdeki benzer çalışmalarla karşılaştırıldığında, önerilen yöntem en yüksek doğruluk, hassasiyet ve özgüllük değerlerine sahiptir. Literatürdeki güncel çalışmalarla karşılaştırıldığında, önerilen sistem oldukça yüksek doğruluk, hassaslık ve özgünlüğe sahiptir.

Çalışmanın geri kalan kısmı aşağıdaki şekilde oluşturulmuştur. İkinci bölümde kullanılan öznitelik setlerinden bahsedilmiştir. Üçüncü bölümde evrişimsel sinir ağlarının genel özellikleri verilmiştir. Önerilen karar mekanizması Bölüm 4'te verilmiştir. Deneysel sonuçlar ve ilgili tüm tartışmalar Bölüm 5 'te verilmiştir. Son bölüm sonuçlara ayrılmıştır.

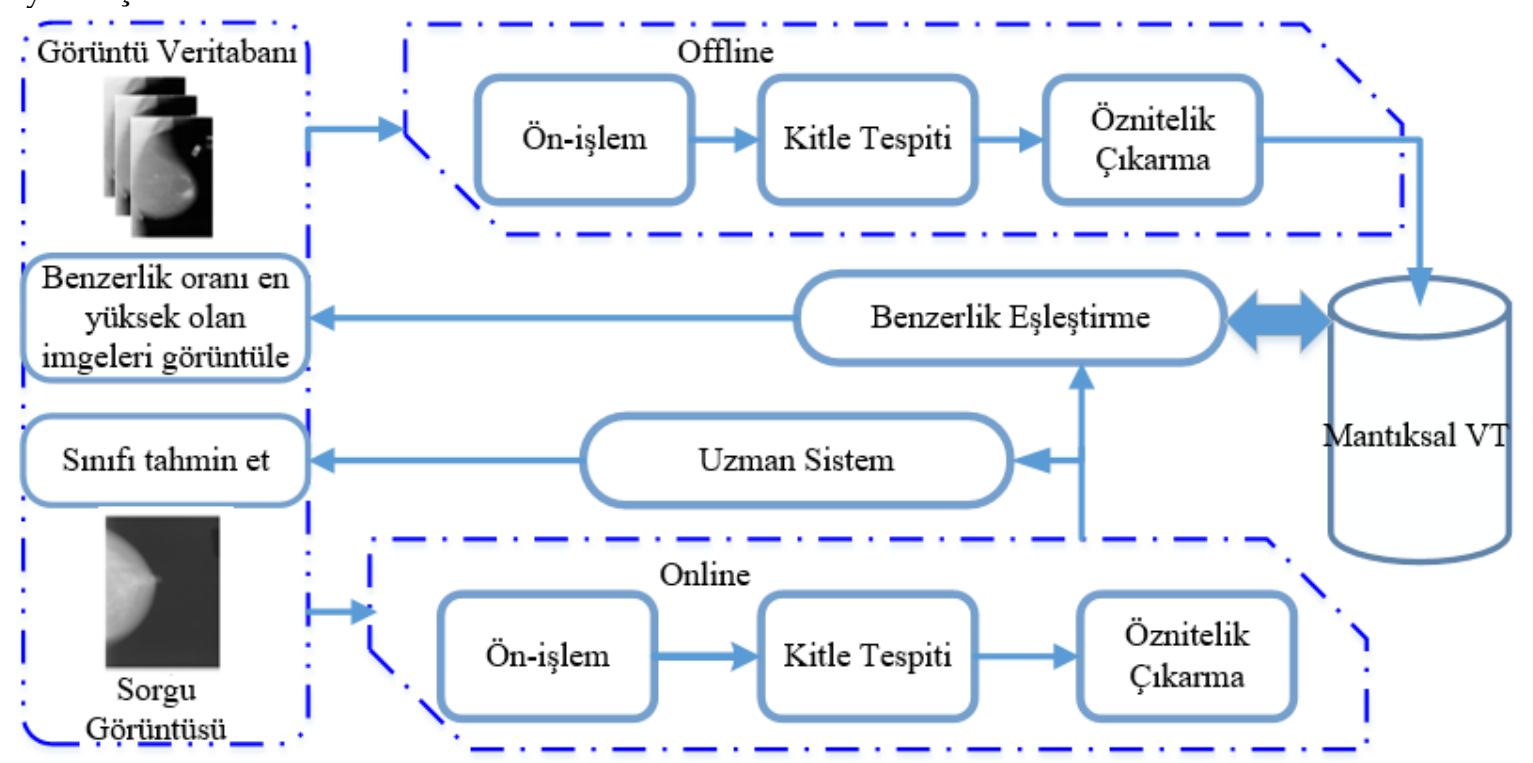

Şekil 1: İTGE sisteminin akış diyagramı (Dataflow diagram of CBIR system)

\section{YÖNTEM ( METHOD )}

Şekil 1, İTGE sisteminin genel olarak akış diyagramını göstermektedir. Önişleme, gürültüyü azaltma ve görüntünün iyileştirilmesi olmak üzere iki adımdan oluşur. Daha sonra, tüm kitle parçalarına ait öznitelik tanımlayıcıları elde edilir. Son olarak, sorgu (test) görüntüsüne en çok benzeyen iyi huylu, kötü huylu ve normal görüntülere erişmek için benzerlik eşleştirmesi gerçekleştirilir. Bu çalışmada 600 adet $227 \times 227$ boyutunda kitle görüntüsünden oluşan Mammographic patches (Deserno et al. 2012) veri seti kullanılmıştır. Mammographic patches veri seti Mammographic Image Analysis Society (MIAS) ve Digital Database for Screening Mammography (DDSM) veri kümelerinden oluşan referans bir veri kümesidir. Bu veri kümesi, mamografik görüntü yamalarını içermektedir. Birçok çalışma, bu veri setini kullanarak algoritmalarının etkinliğini göstermiştir. (Roth et al. 2016) nolu çalışmanın başarılı uygulamalarından ötürü, mamografi görüntüleri $45^{\circ}, 90^{\circ}, 135^{\circ}, 180^{\circ}, 225^{\circ}, 270^{\circ}$ açılarla döndürülür ve veri kümesinin 28 kez büyütülmesi için kırpılır.

Öznitelik çıkarma işleminden sonra, benzerlik hesaplaması yapılır. Sorgu kitle görüntüsünün öznitelik vektörü ile referans görüntülerin özellik vektörleri arasındaki fark, sorgu görüntüsü ve veritabanı arasındaki benzerliği hesaplamak için hesaplanır. Ardından, arama sonuçları ölçülen uzaklık değerlerine göre sıralanır. Çalışmamızda Öklid uzaklığ kullanılmıştır. 
Sorgulanan kitlenin özellik vektörü ile referans görüntülerin özellik vektörleri arasındaki daha küçük mesafe değeri, iki görüntü arasındaki yüksek benzerliği ifade eder.

\section{Öznitelik Seti I'in elde edilmesi (Obtaining of Feature Set I)}

Bu çalışmada, meme kitlelerini tespit etmek için çıkıntı haritasına eşikleme uygulanarak bölütleme gerçekleştiren graf tabanlı görsel çıkıntı (Graph Based Visual Saliency) yöntemi kullanılmıştır. Bu yöntem görüntüdeki bir piksel değerinin, komşulara göre belirginleşmesine neden olan uygun bölgeleri elde etme özelliğine sahiptir. Ayrıca deneysel olarak, bu yöntemin kitle tespitinde oldukça iyi sonuçlar ortaya koyduğu gösterilmiştir (Agrawal, Vatsa, and Singh 2014).

Öznitelik çıkarma, meme kanseri teşhisi açısından kilit rol oynamaktadır. Özellik çıkarma işlemi ancak şüpheli kitle bölgeleri uygun şekilde tanımlandıktan sonra gerçekleştirilebilir. Elde edilen öznitelikler fark edilebilir, objektif ve bağımsız olmalıdır.

Öznitelik kümesi I'i elde etmek için, ilk olarak, kitleye ait 9 adet şekilsel ve 7 adet kitle öznitelik elde edilir. Kitle öznitelikleri ortalama kontrastı, pürüzsüzlük (smoothness), yönelim (orientation), düzgünlük (uniformity), entropi, çevre ve yuvarlaklıktır (circularity). Şekil öznitelikleri ise normalize yarıçap uzunluğu (Normalized Radius Length - NYU), ortalama NYU, standart sapma NYU, entropi NYU, yuvarlaklık oranı (area ratio), ortalama gradyan, standart sapma gradyan, gradyan basıklık (gradient kurtosis) ve gradyan çarpıklıktır (gradient skewness) (Liu and Tang 2014). Son olarak, enerji, korelasyon, entropi, ters fark momenti, kontrast ve homojenliği temsil eden bir 6 adet dokusal öznitelik, gri seviye eş oluşum matrisinden (GLCM) elde edilir (Xie, Li, and Ma 2016). Bir sonraki bölümden öznitelik çıkarma aşamasında kullanılan örneklemesiz contourlet dönüşümü (Non-Subsampled Contourlet transform - NSCT) ve Eig(Hess)-HOG yöntemlerinden bahsedilecektir.

\section{Örneklemesiz contourlet dönüşümü (The Nonsubsampled Contourlet Transform)}

Ayrık dalgacık dönüşümünün medikal görüntü analizindeki farklı uygulamalarına rağmen, pürüzsüz ve yönlü kenarlar gibi görüntülerdeki yönsel bilgiyi yakalamada bazı sınırlamaları bulunmaktadır (Meselhy Eltoukhy, Faye, and Belhaouari Samir 2010). Örneğin, ortogonal dalgacıklar sadece yatay, dikey ve çapraz yöndeki süreksizlikleri göz önüne aldığından elde edilen bu öznitelikler, iyi huylu ve kötü huylu kitlelere ait kenar ve dokuları temsil eden pürüzsüz eğrileri etkili bir şekilde ifade edememektedir. Dış hatları pürüzsüz olan kenarları doğrudan ayrık domainde etkin bir şekilde ifade etmek için, contourlet dönüşümü Do ve Vetterli (Do and Vetterli 2005) tarafından önerilmiştir. Contourlet dönüşümü görüntüyü dalgacık dönüşümünden daha etkili bir şekilde ifade etmesine rağmen, aşağı örnekleme ve yukarı örneklemeye bağlı olarak kayma-değişmez (shift-invariant) değildir. Örneklemesiz contourlet dönüşümü, Cunha ve diğerleri (Da Cunha, Zhou, and Do 2006) tarafından bu kısıtlamayı telafi etmek için önerildi ve onun yararlı özellikleri nedeniyle, bu çalışmada meme kitlelerini ifade etmek için kullanılmıştır. Öznitelik çıkarımı için, 4 seviyeli örneklemesiz contourlet dönüşümünden elde edilen ortalama, varyans, enerji, entropi, çarpıklık ve basıklık parametreleri kullanılmıştır.

Örnek bir kitle için, örneklemesiz contourlet dönüşümü Şekil 2'de gösterilmiştir. Görüntü, dört seviyeye ayrılmış ve sonuçta bir, iki ve sekiz alt bant elde edilmiştir.

\section{Eig(Hess)-HOG (Eig(Hess) Histogram of Oriented Gradients)}

Geleneksel HOG yönteminde görüntünün gradyanı klasik türev işlemi ile yapılmaktadır. Gradyan, yön ve büyüklüğü bilgilerini içeren iki boyutlu bir vektördür. Bir görüntünün gradyanı denklem (1) ve (2)'de görüldüğü gibi ifade edilir:

$$
\begin{aligned}
& \nabla I(x, y)=\left[\begin{array}{l}
I_{x}(x, y) \\
I_{y}(x, y)
\end{array}\right] \\
& I_{x} \cong I(x+1, y)-I(x, y)
\end{aligned}
$$




$$
I_{y} \cong I(x, y+1)-I(x, y)
$$

$I_{x}$ ve $I_{y}$ görüntünün sırasıyla birinci dereceden yatay ve dikey türevlerini ifade etmektedir. Ancak, bir görüntünün lokal davranışlarını incelemek için, imgenin ikinci dereceden kısmi türevlerini ifade eden Hessian matrisi kullanılır (Hanbay et al. 2015). Hessian matrisi denklem (3)'deki gibi ifade edilir:

$$
H_{\sigma}(x, y)=\left[\begin{array}{ll}
I_{x x} & I_{x y} \\
I_{y x} & I_{y y}
\end{array}\right]
$$

$I_{x x}, I_{y y}, I_{x y}$ görüntünün sırasıyla $x, y, x y$ yönündeki ikinci dereceden türevleridir. Klasik gradyan ile kıyaslandığında, Hessian matrisi imgedeki temel yönlerin belirlenmesinde klasik gradyana göre daha uygundur. Hessian matrisinin temel amacı, imge yüzeyindeki temel yönleri ve temel eğrilikleri belirlemektir. Hessian matrisinin öz değerleri temel eğrilikler olarak ifade edilir ve bu öz değerlerin çarpımı aynı zamanda Hessian matrisinin determinantına eşittir. $G_{x x}, G_{y y}, G_{x y}$ giriş imgesi I'nın sırasıyla $x, y, x y$ yönündeki ikinci dereceden kısmi türevlerini ifade etmektedir.

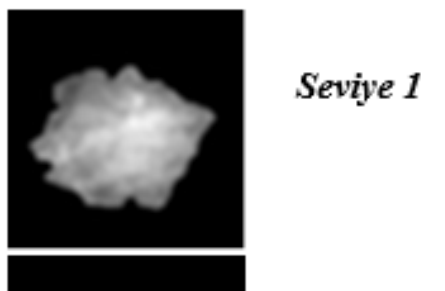

Seviye 2
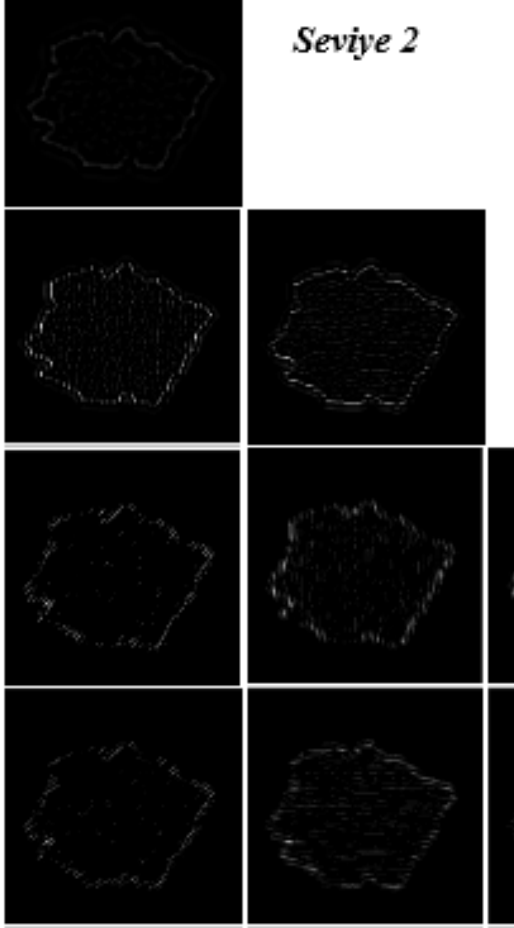

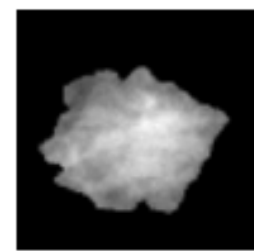

(a)

\section{Seviye 3}

(b)

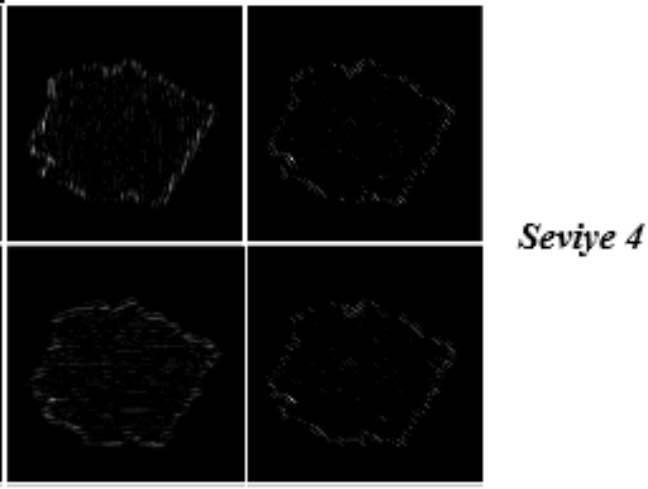

Şekil 1: Örnek kitleye ait örneklemesiz contourlet dönüşümü : (a) Örnek kitle, (b) 4 seviye ayrışma sonucu (The Nonsubsampled contourlet transform of breast mass sample: (a) ROI sample, (b) four-level decomposition) 
Hessian matrisinin öz değerleri ( $\lambda_{1}$ ve $\lambda_{2}$ ) denklem (4) gibi hesaplanır [21]:

$$
\lambda_{1,2}= \pm \sqrt{\frac{\left(I * G_{x x}-I * G_{y y}\right)^{2}}{4}+\left(I * G_{x y}\right)^{2}}+\frac{I * G_{x x}-I * G_{y y}}{2}
$$

Gradyan yönelim $(\theta)$ ve büyüklüğü (m) değerleri denklem. (5) ve (6) de görüldüğü gibi hesaplanır.

$$
\begin{aligned}
& m=\sqrt{\left(\lambda_{1}\right)^{2}+\left(\lambda_{2}\right)^{2}} \\
& \theta=\arctan \left(\frac{\lambda_{2}}{\lambda_{1}}\right)
\end{aligned}
$$

Sonuç olarak bir kitleye ait 128 adet öznitelik elde edilmiştir. Şekil. 3 örnek kitle için hessian matrisin özdeğerlerinin hesaplanması göstermektedir. Öznitelik kümesi I'in nasıl elde edildiği özet olarak Şekil 4'de görülmektedir.

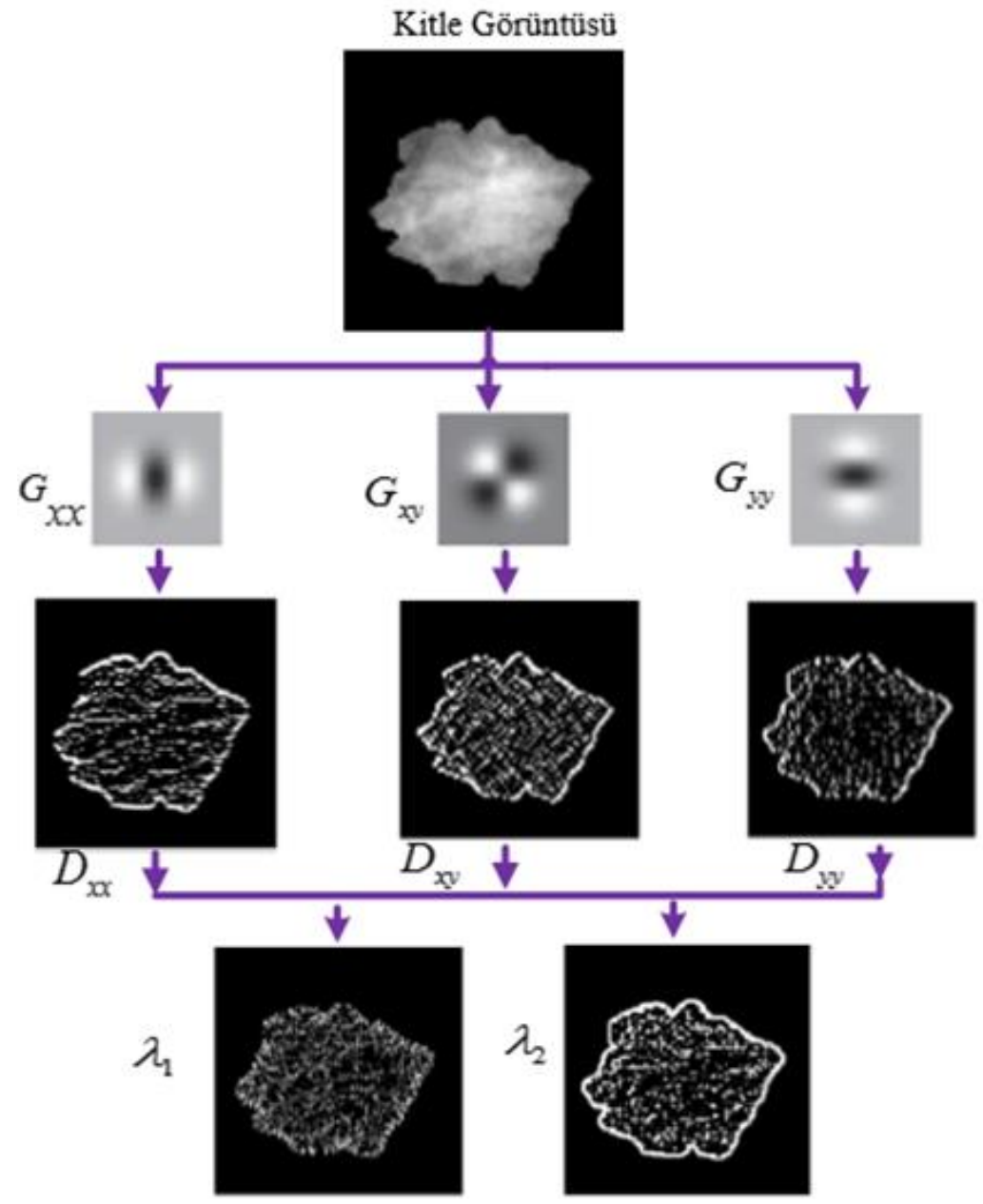

Şekil 2: Örnek kitle için hessian matrisin öz-değerlerinin hesaplanması

(Computation of eigenvalues of the hessian matrix for a breast mass sample) 

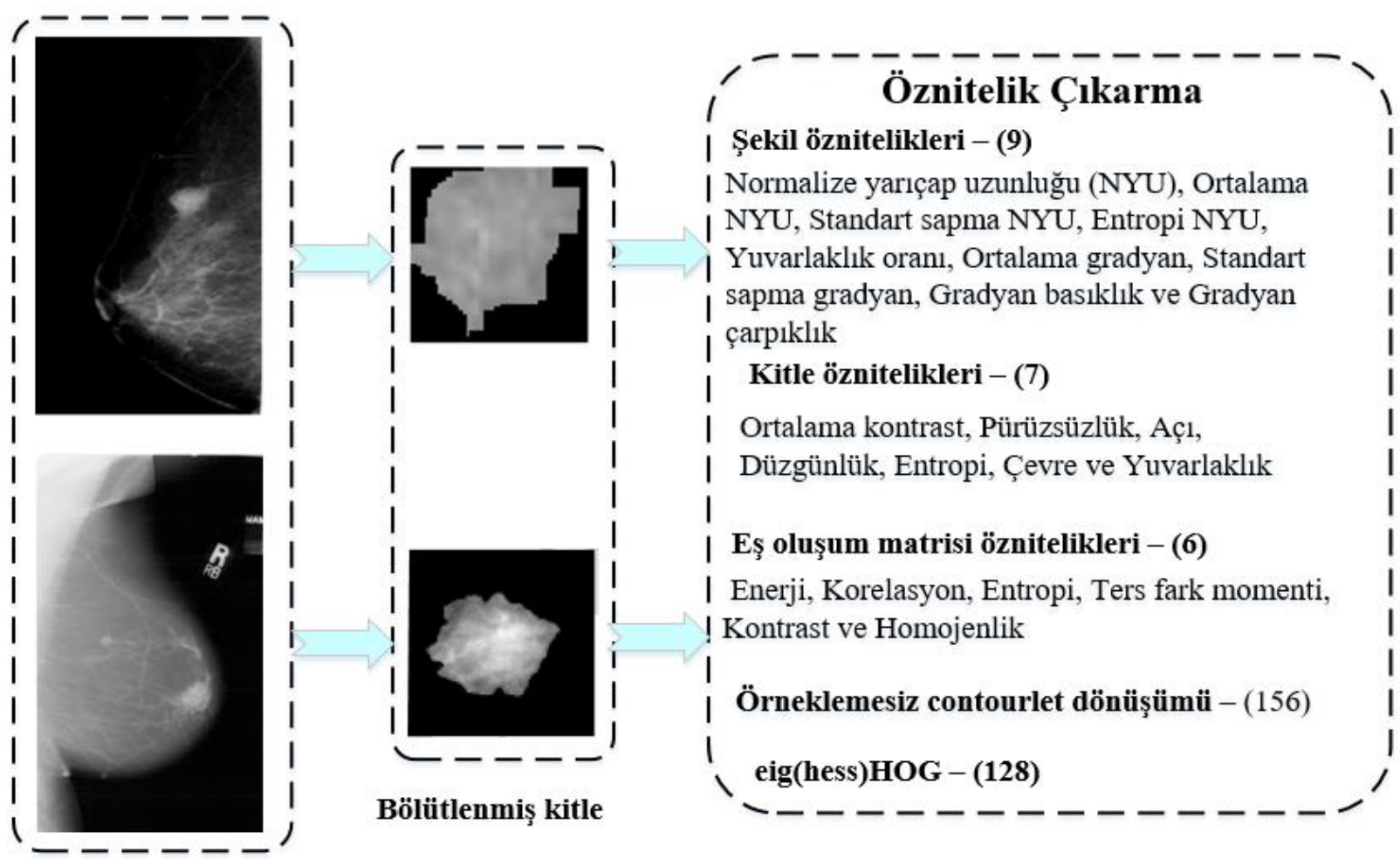

Standart görüntü

Şekil 3: Örnek bir mamogram ile öznitelik çıkarma aşaması (Feature extraction stage with an example mammogram)

\section{Öznitelik Seti II'in elde edilmesi (Obtaining of Feature Set II)}

Elde edilen ikinci öznitelik seti için derin öğrenme tabanlı öznitelik çıarma sistemi önerilmiştir. Mammographic patches veri seti kullanılarak, eğitimli evrişimsel Sinir Ağı (Convolutional Neural Networks, $\mathrm{CNN}$ ) üzerinde ince ayar (fine tuning) işlemi uygulanır. Elde edilen yapı, sonraki aşamalarda öznitelik çıkarmak için kullanılır. Ardından, eğitimli modelin fc7 katmanından üst düzey öznitelikler çıkarılır. Böylece ikinci öznitelik kümesi elde edilir.

Meme kanseri tespitinde yeterince büyük bir veri seti bulunmamaktadır. Bu sorunu çözmek için, evrişimsel sinir ağımız ilk önce 1 milyondan fazla etiketli doğal resim içeren bir veri kümesi olan ILSVRC (Krizhevsky, Sutskever, and Hinton 2012) üzerinde eğitilmiştir. Bununla birlikte, veri kümesindeki doğal görüntüler RGB formatındadır ve gri seviyeli mamografi görüntüleriyle alâkalı değildir. Bu nedenle, veri kümesi gri seviyeye dönüştürülür. A ̆̆ yapısı, (Donahue et al. 2013)'den esinlenmiştir. Başarılı sonuçlarından dolayı eğitim stratejisi için (W. Zhang et al. 2015) uygulanmıştır. Denetimli bir öğrenme sürecidir, öğrenme oranı 0.01 olarak başlatılmıştır. Eğitim, doğal imgeler için 100 iterasyon devam etmiştir. Daha sonra mamografi görüntüleri üzerinde öğrenme hızı 0.00001 olarak başlatılmış ve ikinci aşamada 100 iterasyon devam etmiştir. Eğitim sürecinde ağımızı optimize etmek için çok basit ve verimli olan Stochastic gradient descent (SGD) yöntemi (Bottou 2010) kullanılmıştır. Kullanılan evrişimsel sinir ağının her katmanına ait parametreler (Jiao et al. 2016)' da detaylı olarak verilmiştir.

Ardından, önceden öğrenilen modeli kullanarak ince ayar işlemi uygulanır, mimariye göre düzenlenir ve daha önceden öğrenilen model ağırlıkları ile mamografi görüntüleri için eğitime devam edilir. Bu çalışmada kullanılan veri seti 600 (Deserno et al. 2012) kitle görüntüsünden oluşmaktadır. (Roth et al. 2016)'nın başarılı bir şekilde uygulanmasından dolayı veri setini artırmak amacılla mamografi görüntüleri, $45^{\circ}, 90^{\circ}, 135^{\circ}, 180^{\circ}, 225^{\circ}, 270^{\circ}$ açlarla döndürülür ve $2 \times 2$ şeklinde bölünür.

\section{EVRIŞSIMSEL SİNiR AĞLARI (Convolutional Neural Networks)}

Son yıllarda, derin öğrenme bilgisayar görmesi ve medikal görüntü analizi (Roth et al. 2016; W. Zhang et al. 2013) uygulamalarında dikkate değer bir performans göstermiştir. Evrişimsel sinir ağları derin öğrenme yöntemlerinden 
biridir. Derin öğrenme yöntemleri arasında evrişimsel sinir ağları semantik bölütleme, nesne algılama, yüz tanıma ve sınıflandırma gibi bilgisayar görmesi uygulamalarında oldukça popüler hale gelmiştir. Geleneksel makine öğrenmesinde, belirli bir görevi yerine getirecek bir makine öğrenme sistemi geliştirmek için dikkat değer biçimde alan uzmanlı̆̆ formatta işleyemez. Bu sistemlerde, ham veriler doğrudan sistem girişine verilir ve bu veriler basit doğrusal olmayan dönüşümlere tabii tutulur. Böylece, çok sayıda dönüşüme tabii tutulan sistem, çok karmaşık fonksiyonları öğrenme kabiliyeti kazanır. Sonuç olarak, evrişimsel sinir ağları tabanlı yöntemlerin geleneksel yöntemlerden önemli ölçüde daha iyi performans sergilediği görülmektedir.

Evrişimsel sinir ağları katmanların form ve işlevleri açısından klasik sinir ağlarından farklıdır. Klasik ağlarda, katmanlar tek boyutludur ve bu katmanlardaki nöronlar birbirlerine tamamen bağlıdır. Evrişimsel sinir ağları ise tamamen bağlı olan nöronları kullanmak yerine yerel olarak bağlı nöronların kullanılmasını önerir. Evrişimsel sinir ağları, konvolüsyon, toparlama, normalizasyon ve tam bağlı katman olmak üzere 4 katmandan meydana gelmektedir. Ağ kapasitesi, katman sayısı, filtre sayısı ve boyutuyla ilişkilidir.

Konvolüsyon katmanı tipi evrişimsel sinir ağları yapısının çekirdeğidir. Bir konvolüsyon katmanı, nöronların bir araya toplanmasından oluşan çoklu özellik haritalarından oluşur. Konvolüsyon alt katmanı aynı filtreyi farklı konumlara uygular. Verilerin dağılımı farklı konumlarda aynı olduğundan, aynı filtrenin görüntülerin farklı yerlerine uygulanması, özellikle medikal görüntüler için oldukça mantıklıdır. Toparlama (pooling) işlemi, uzaysal olarak yakın öznitelik haritalarını özetlemektedir. Önemli örüntülerin değişmezliğini sağlamak için en ayırdedici özniteliklerin bir sonraki katmana aktarılması için kullanılır. Ortalama, maksimum ve L2-norm işlemleri en yaygın örneklerdir. Böylece, bir sonraki katmandaki verinin boyutunu azalmış olur. Boyutun azaltılması sayesinde, hesaplama zamanı ve parametre sayısı azalır, bu sayede ezberleme önlenir (Chougrad, Zouaki, and Alheyane 2018; Sun et al. 2017). Toparlama işleminin ardından sistemin genelleme kabiliyetini artırmak amacıyla L2-Norm nomalizasyon işlemi uygulanır.

\section{ÖNERILEN KARAR MEKANIZMASI (Proposed Decision Mechanism)}

Önerilen sistemde, ağın fc7 katmanından üst düzey öznitelikler elde edilmiştir. Ardından, elde eden iki farklı öznitelik setine dayalı olarak kitlenin türünü belirlemek için iki AÖM sınıflandırıcısı kullanılmıştır. Deneylerde, 10 katlamalı çapraz doğrulama uygulanmıştır. Buna ek olarak, veri kümesindeki her görüntü, performansı artırmak için evrişimsel sinir ağına verilmeden önce normalize edilmiştir.

Önerilen sistemin temel amacı göğüs kitlelerinin global ve lokal ayrıntılarını elde etmektir. Kitlenin tüm yönleriyle ifade edilmesine yardımcı olmaktadır. Karar destek sistemimiz doktorların teşhis mantığını taklit etmektedir. Genellikle semptom karşılaştırmalarından meydana gelmektedir. Elde edilen derin özellikler tüm sistemde önemli rol oynamıştır. Çünkü insan bilişsel sisteminin bu derin özelliklere uygun olduğu düşünülmektedir. ILSVRC veri seti CNN modelimizi eğitmek için seçilmiştir.

İki sınıflandırıcının çıkışlarını ilişkilendirmek için Şekil 5'deki önerilen yöntem kullanılmıştır. Test görüntülerinden öznitelik seti I ve II önceki bölümlerde bahsedildiği gibi elde edilir. Öznitelik seti I, şekil, kitle, doku, örneklemesiz contourlet dönüşümü ve eig(Hess) -HOG öznitelikleri olmak üzere beş farklı öznitelikten oluşmaktadır. Öznitelik seti II, evrişimsel sinir ağı kullanılarak elde edilen yüksek seviye özniteliklerdir. Ardından, elde edilen özniteliklerin sınıflandırılması ve erişimi için iki farklı AÖM sınıflandırıcısı kullanılmıştır.

Test aşamasında ise, iki sınıflandırıcının çıkışları aynı ise, çıkışlar Şekil 5'de gösterildiği gibi doğru olarak kabul edilir. Test görüntülerinin çıkışları farklı ise, bunlar belirsiz küme ile ilişkilendirilir. Belirsiz test kümesindeki her görüntünün hangi türe ait olduğuna karar vermek için, gri seviye yoğunluğu, görüntülerin iyi huylu ve kötü huylu olanlara yakınlı̆̆ını hesaplamak için kullanılır. Yakınlık parametresini hesaplarken, hiyerarşik k-ortalama kümeleme yöntemi, kullanılmıştır (Vedaldi and Fulkerson 2010). Sonuç olarak, yakınlık parametresi göz önüne alınarak, belirsiz küme ikiye ayrılır. 


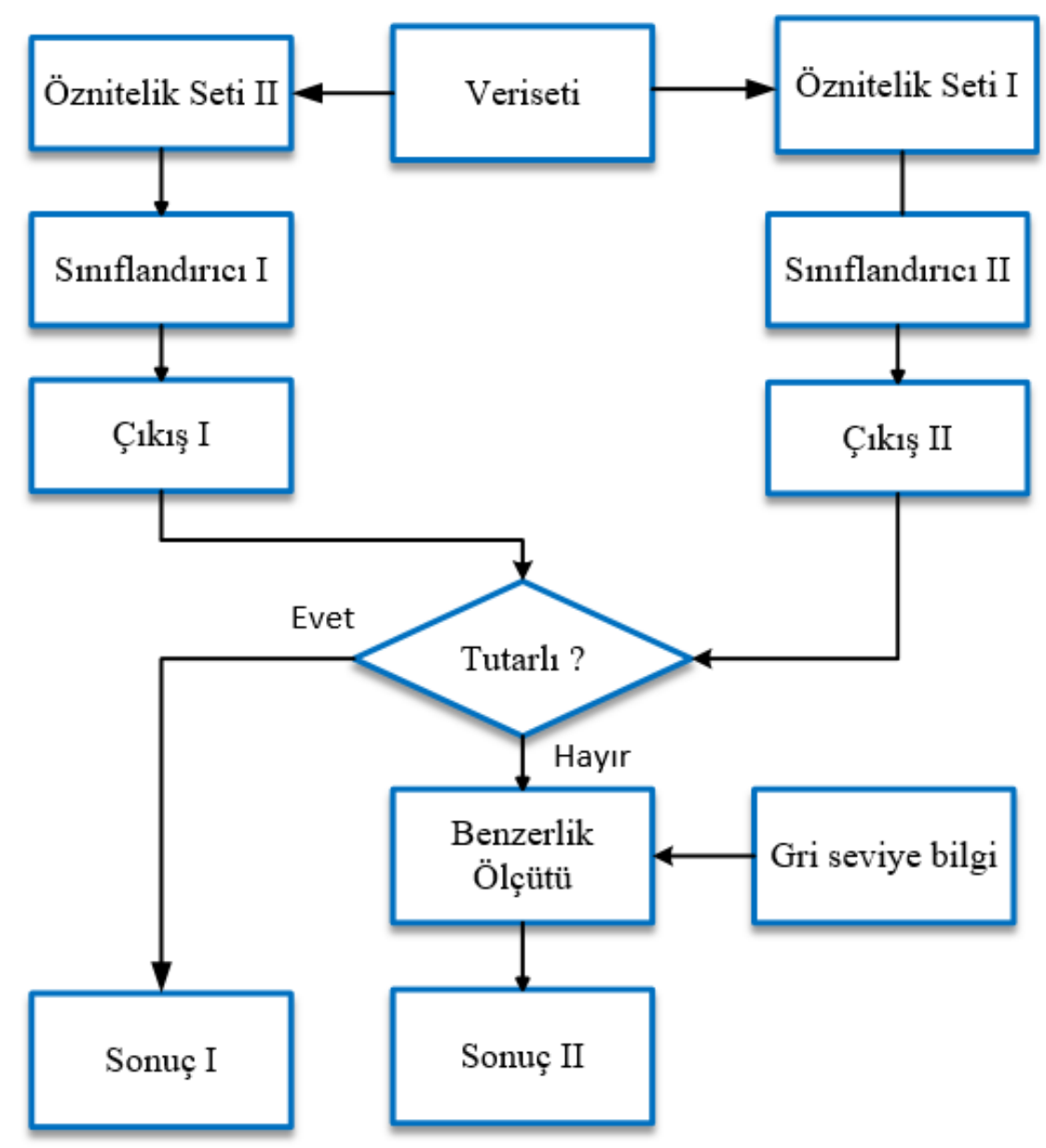

Şekil 4: Önerilen karar mekanizması (Proposed Decision Mechanism)

\section{DENEYSEL SONUÇLAR (Experimental Results)}

Gögüs kitlelerini normal veya anormal (iki-sınfflı) veya normal, iyi huylu ve kötü huylu olarak sınıflandırmak için genelleme performansı nedeniyle AÖM sınıflandırıcısı kullanılmıştır.

\section{Deney tasarımı (Experimental Design)}

Deneylerimizde 10 katlamalı çapraz doğrulama kullanılmıştır. Böylece sınıflandırıcının genel performansı, garanti edilmiştir. AÖM sınıflandırıcısının gizli katmanlarında ve çıkış katmanında sırasıyla tanjant sigmoid ve doğrusal aktivasyon fonksiyonları kullanılmıştır Gizli katman sayısı (Xie, Li, and Ma 2016) çalışmasının başarılı sonuçlarından ötürü 700 olarak belirlenmiştir. Önerilen yaklaşımın farklı alanlarındaki performansını ölçmek için, her karışıklık matrisi (confusion matrix) için duyarlılık (sensitivity) ve özgüllük (specificity) değerleri hesaplanmıştır. Sınıflandırma yaklaşımlarının performansını ölçmek için doğruluk (accuracy), duyarlılık ve özgüllük parametreleri kullanılmıştır. Sınıflandırma sonuçlarının başarım bilgileri karışıklık matrisi ile ifade edilebilir. Tablo 1'de karışıklık matrisi görülmektedir. GP, doğru şekilde sınıflandırılan kanserli vaka sayısını, YP sağlıklı olduğu halde kanser teşhisi konanların sayısını, GN doğru şekilde sağlıklı teşhisi konanların sayısını, YN kanser olduğu halde sağlıklı teşhisi konanların sayısını ifade etmektedir. Deneyler sonuçlar MATLAB geliştirme ortamında elde edilmiştir. 
Tablo 1: Karışıklık Matrisi (Confusion Matrix)

\begin{tabular}{|cccc}
\multicolumn{3}{c}{} & \multicolumn{2}{c}{ Gerçek Durum } \\
\cline { 2 - 4 } & Pozitif & Pozçitif & Negatif \\
& Negozitif (GP) & Yanlış negatif (YN) \\
\cline { 1 - 3 } & Negatif & Yanlış pozitif (YP) & Gerçek negatif (GN)
\end{tabular}

Doğruluk, Doğru sınıflandırılmış örnek sayısının (GP +GN), toplam örnek sayısına $(G P+G N+Y P+Y N)$ oranıdır. Duyarlılık, Doğru sınıflandırılmış pozitif örnek sayısının toplam pozitif örnek sayısına oranıdır. Özgüllük gerçek negatif sayısının gerçek negatif ile yanlış pozitif sayılarının toplamına bölümüne eşittir. Doğruluk, Duyarlılık ve Özgüllük değerlerinin nasıl hesaplandığı sırasıyla denklem 7,8,9'da görülmektedir.

$$
\begin{gathered}
D O G R U L U K=\frac{G P+G N}{G P+Y N+G N+\mathrm{Y} P} \\
D U Y A R L I L I K=\frac{G P}{G P+Y P} \\
\ddot{O} Z G \ddot{U} L L \ddot{U} K=\frac{G N}{G N+Y N}
\end{gathered}
$$

Sistemin görüntü erişim performansı kesinlik-duyarlılık (Precision-Recall, PR) eğrileri ile değerlendirilmiştir. Kesinlik-duyarlılık eğrileri bilgi erişiminde sıklıkla kullanılmaktadır. Deney tasarımımızda, test veri kümesindeki her imge bir sorgu görüntüsü olarak kullanılmıştır. İki sınıf ve üç sınıf performansları, kesinlik-duyarlılık eğrileri ile kıyaslanmıştır.

Şekil 6, öznitelik seti I,II ve önerilen yöntem için ROC (reciever operator characteristics curve) eğrisi sonuçlarını göstermektedir. Şekil 6'da görüldüğü gibi, öznitelik seti I,II ayrı ayrı kullanıldığında istenilen performansı gösterememektedir. Sonuç olarak, önerilen karar mekanizması ile sistem performansının dikkate değer oranda iyileştirildiği görülmektedir. Ayrıca, kitlelerin yüksek seviyeli derin özellikler ile ifade edilebileceği ortaya konulmuştur. Tablo 2' de önerilen karar mekanizmasının sınıflandırma performansına ait, doğruluk, hassasiyet ve özgüllük değerleri görülmektedir. Şekil 6'da öznitelik seti I'in öznitelik seti II'ye göre daha etkili olduğu görülmektedir. Tablo 3, önerilen sistemin literatürde var olan güncel çalışmalarla performans kıyaslamasını göstermektedir. Tabloda görüldüğü üzere önerilen sistem doğruluk, duyarlılık ve özgüllük bakımından oldukça iyi performans göstermektedir. Ayrıca, en iyi doğruluk, hassaslık ve özgüllük değerlerinin önerilen sistem tarafından elde edildiği görülmektedir.

Tablo 2: Önerilen sistemin sınıflandırma başarısı sonuçları (Classification performance of proposed decision mechanism)

\begin{tabular}{r|ccc}
$\#$ & Doğruluk(\%) & Hassaslık(\%) & Özqüllük(\%) \\
\hline 1 & 97.9256 & 97.0549 & 93.4207 \\
2 & 99.0522 & 97.7084 & 97.8459 \\
3 & 94.2580 & 98.6837 & 95.0127 \\
4 & 91.8532 & 91.0009 & 96.3730 \\
5 & 98.2569 & 95.6649 & 93.2901 \\
6 & 97.4948 & 96.7060 & 92.8495 \\
7 & 98.9437 & 97.4345 & 94.8181 \\
8 & 98.6504 & 93.3903 & 94.4945 \\
9 & 99.5822 & 93.9883 & 97.3896 \\
10 & 97.1248 & 97.5814 & 96.2121 \\
Ort. & 97.3142 & 95.9213 & 95.1706
\end{tabular}




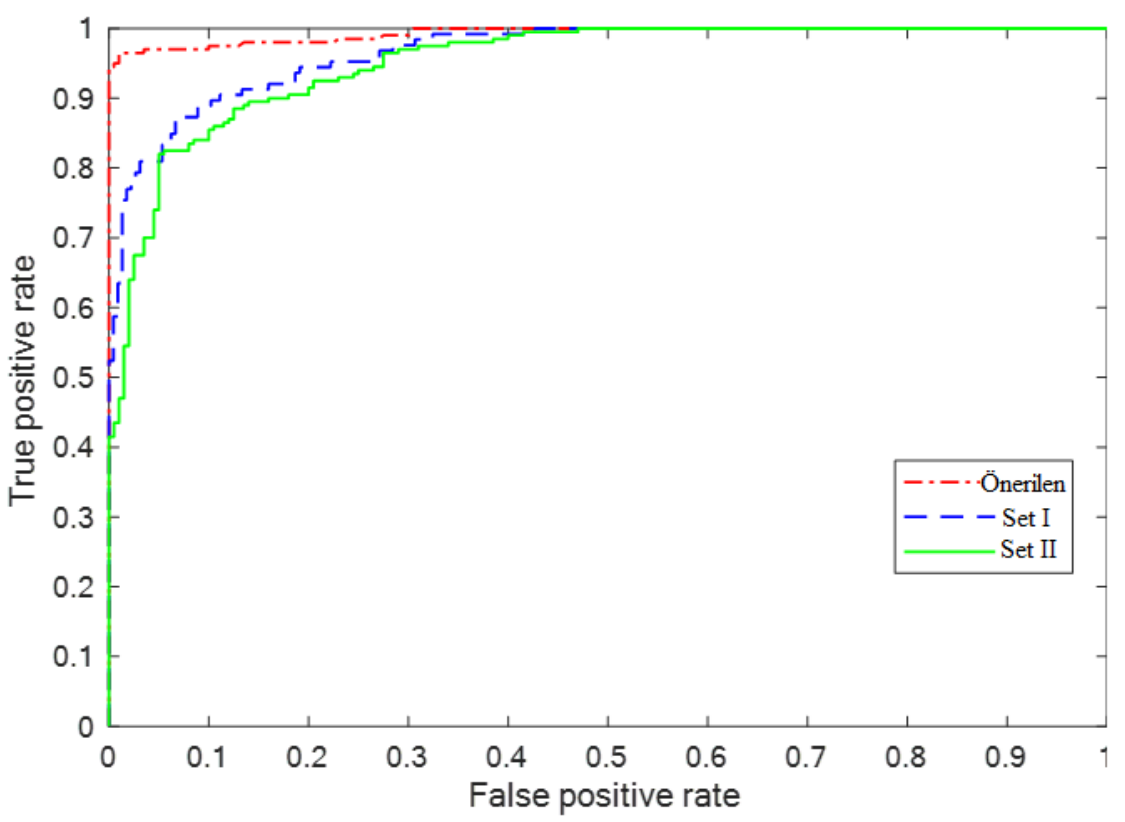

Şekil 5: Farklı öznitelik setleri için ROC eğrileri

(ROC curves of different feature sets)

Tablo 3: Önerilen yöntemin literatür ile kıyaslanması

(Comparison of proposed framework with state of art systems )

\begin{tabular}{r|cccc} 
Makale & Sinıflandırıcı & Doğruluk(\%) & Hassaslık(\%) & Özgünlük(\%) \\
\hline Wang et al. (Wang, Li, and Gao 2014) & SVM & 92.74 & - & - \\
B. Swiderski et al. (Swiderski et al. 2017) & SVM & 90.9 & 96.7 & 80.1 \\
M. Jadoon et al, (Jadoon et al. 2017) & SVM & 83.74 & - & - \\
Liu and Tang (Liu and Tang 2014) & SVM & 93.00 & 92.00 & 92.00 \\
Dong et al., (Dong et al. 2015) & GA-SVM & 93.24 & 94.78 & 91.76 \\
Jen E Yu, (Jen and Yu 2015) & ADC & - & 86.0 & 84.0 \\
N. Gedik et al.(Gedik, Atasoy, and Sevim & SVM & 93.95 & 87.23 & 91.39 \\
2016) & & & & \\
R. Rouhi et al., (Rouhi et al. 2015) & MLP & 95.01 & 96.25 & 93.78 \\
Jiao et al. (Jiao et al. 2016) & CNN & 96.7 & - & - \\
Önerilen Sistem & ELM & 97.31 & 95.92 & 95.17
\end{tabular}

Şekil 7, öznitelik seti I,II ve önerilen yöntem için kesinlik-duyarlılık eğrileri sonuçlarını göstermektedir. Sonuç olarak, önerilen karar mekanizmasının tüm diğer öznitelik setlerinden daha iyi performansa sahip olduğu görülmektedir. Elde edilen sonuçlar, göğüs kitlelerinin karakteristiklerinin derin özellik tabanlı karar mekanizması ile daha iyi temsil edildiğini doğrulamaktadır. Bu karar mekanizması ile ilgili olarak, \% 3'lük duyarlılık ve \% 97 hassasiyet değeri ile önerilen İTGE sistemi, 29824 sorgu görüntüsünden 28929'una doğru olarak erişmeyi sağlamıştır. Ayrıca, Şekil 6 ve Şekil 7 AÖM sınıflandırıcılarının tek başlarına kullanıldı̆̆ında elde edilen sınıflandırma ve görüntü erişim sonuçlarını ifade etmektedir. 


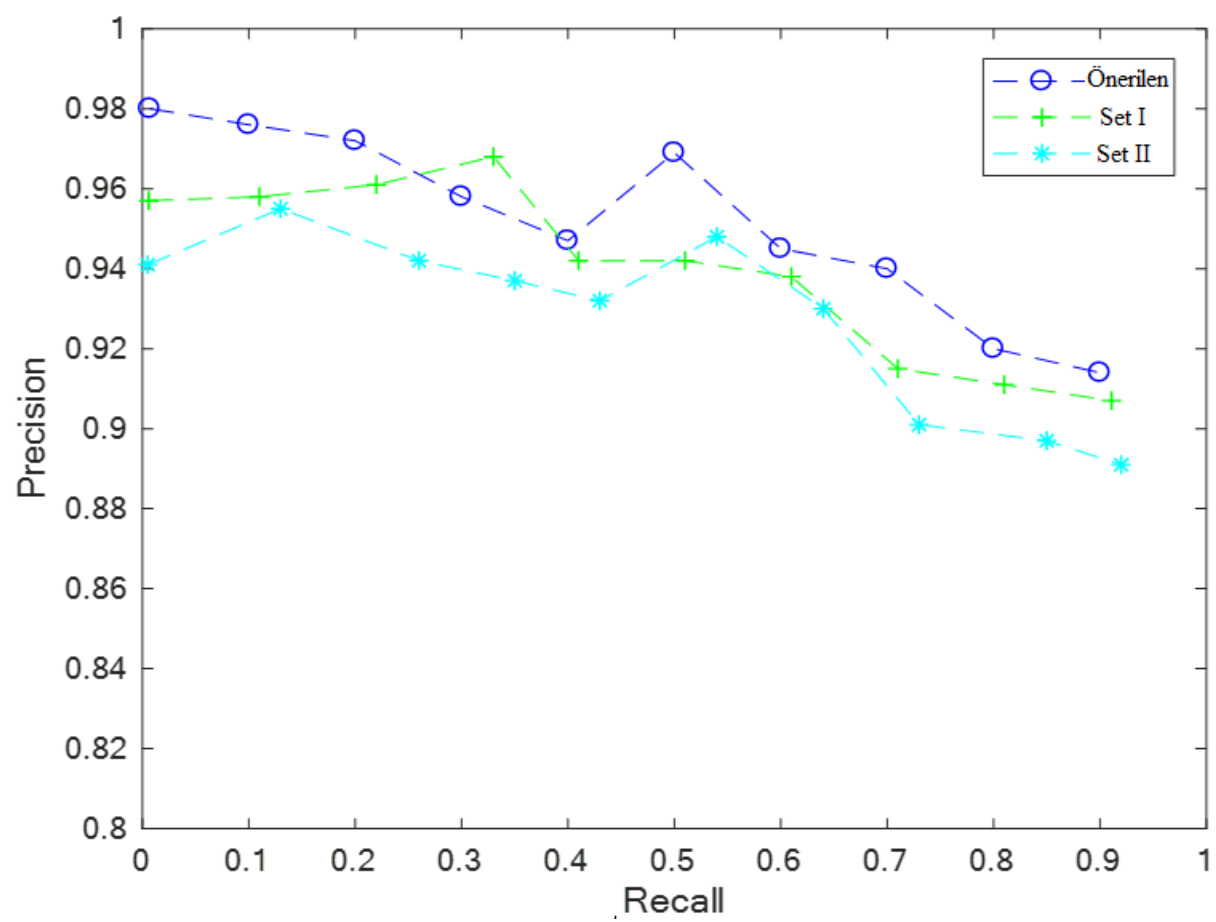

Şekil 6: Farklı öznitelik setlerine ait performans sonuçları

(Performance evaluation of different feature sets)

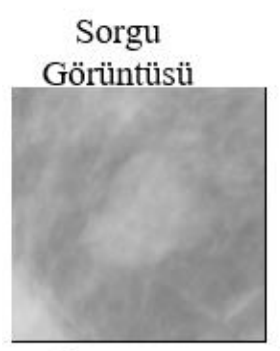

İyi huylu

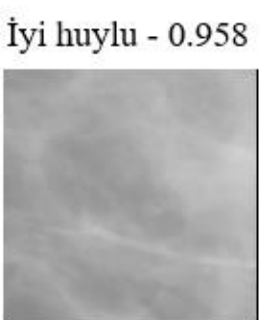

İyi huylu -0.811
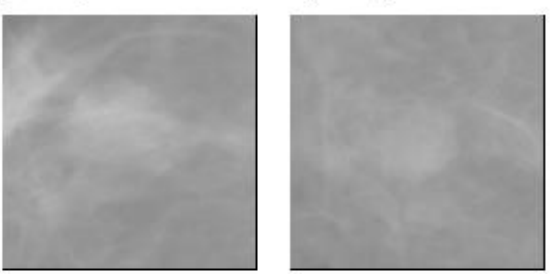

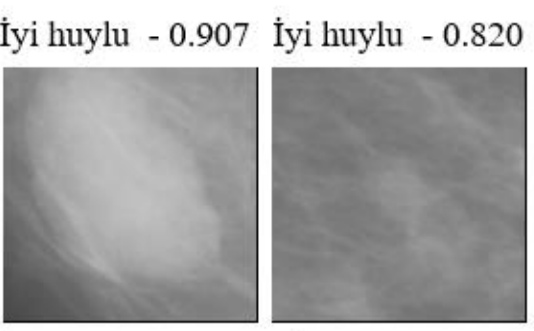

İyi huylu -0.725 İyi huylu -0.698
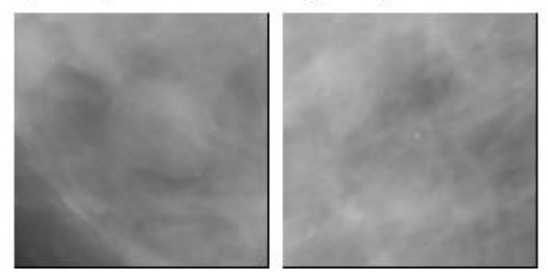

Şekil 7: İyi huylu örnek sorgu görüntüsüne ait erişim sonuçları

(Retrieval results for benign query image)

Şekil 8, önerilen sistem için, örnek iyi huylu bir sorgu kitle görüntüsüne ait sorgu sonuçlarını göstermektedir. Getirilen tüm görüntüler iyi huyludur. Şekil 9'da gösterilen diğer örnek kötü huyluya aittir. Elde edilen tüm görüntüler sorgu görüntüsüyle aynı kategoriye aittir. 


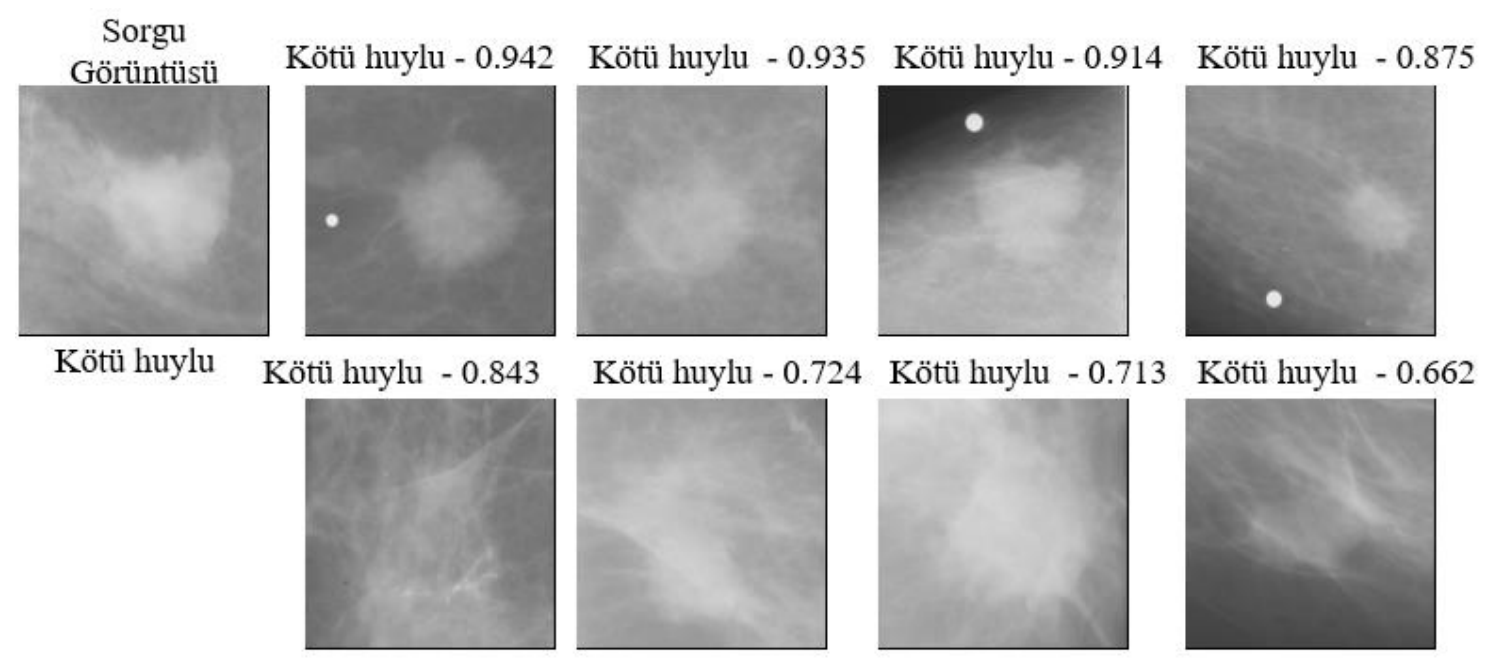

Şekil 8: Kötü huylu örnek sorgu görüntüsüne ait erişim sonuçları

(Retrieval results for malignant query image)

Yapılan deneyler, geleneksel öznitelik çıkarma yöntemlerinin mamogram sınıflandırma ve erişimi için yeterli olmadığını açıkça göstermektedir. Önerilen sistem, bir evrişimsel sinir ağları modelinin derin özniteliklerinden yararlanmaktadır. Önerilen karar mekanizmasının, mamogram sınıflandırma ve erişimi için yeterli performans gösterdiği ortaya konulmuştur. Deneysel sonuçlar, önerilen karar mekanizmasının, literatürdeki yöntemlerden üstünlüğünü ortaya koymaktadır. Ayrıca, geniş veri setlerinin mevcut olmadığı medikal alanlarda önerilen sistemin etkinliği ortaya konulmuştur.

\section{SONUÇLAR (Conclusions)}

Meme kanseri, hücrelerde kötü huylu lezyon gelişimini göstermektedir. Akciğer kanseri sonrasında dünyadaki en yaygın kanser türüdür. Her 8 kadından birinin hayatlarının belirli bir zamanında göğüs kanseri geçirdiği bildirilmektedir. Erkeklerde görülmesine karşın, kadın vakaları erkek vakalardan 100 kat fazladır. Göğüs kanserine karşı en iyi önleyici yöntem erken teşhis yöntemidir. $\mathrm{Bu}$ nedenle erken tespiti artırmak için çeşitli yöntemler geliştirilmektedir. Bilgisayar destekli tanı sistemleri, doktorlara tıbbi görüntüleri yorumlamada yardımcı olmak için kullanılmaktadır. Bilgisayar destekli tanı sistemleri yardımcı bir teşhis sistemidir; nihai karar doktora aittir. Bu çalışmada, mamogramlar için otomatik kitle tespiti, sınıflandırılması ve erişimi için derin öğrenme tabanlı bir karar destek sistemi geliştirilmiştir. Geliştirilen sistem, mamografi görüntülerinin içerik tabanlı erişimi ve sınıflandırılması için değerlendirilmiştir. Deneysel sonuçlar, önerilen sistemin etkililiğini ve gerçek zamanlı klinik uygulamalardaki kullanılabilirliğini göstermektedir.

\section{KAYNAKLAR (REFERENCES)}

Agrawal, Praful, Mayank Vatsa, and Richa Singh. 2014. “Saliency Based Mass Detection from Screening Mammograms." Signal Processing 99. Elsevier BV: 29-47.

Alto, Hilary. 2007. "Errata: Content-Based Retrieval and Analysis of Mammographic Masses." Journal of Electronic Imaging 16 (1): 019801. https://doi.org/10.1117/1.2713758.

"American Cancer Society Published Second Edition of Global Cancer Atlas." 2015. Oncology Times 37 (1). Ovid Technologies (Wolters Kluwer Health): 34.

Bottou, Léon. 2010. “Large-Scale Machine Learning with Stochastic Gradient Descent." In Proceedings of COMPSTAT'2010, 177-86. Heidelberg: Physica-Verlag HD.

Chougrad, Hiba, Hamid Zouaki, and Omar Alheyane. 2018. “Deep Convolutional Neural Networks for 
Breast Cancer Screening." Computer Methods and Programs in Biomedicine 157 (April). Elsevier: 19-30. https://doi.org/10.1016/J.CMPB.2018.01.011.

Cunha, A L Da, J Zhou, and M N Do. 2006. "The Nonsubsampled Contourlet Transform: Theory, Design, and Applications." IEEE Transactions on Image Processing 15 (10). Institute of Electrical and Electronics Engineers (IEEE): 3089-3101. https://doi.org/10.1109/tip.2006.877507.

Deserno, Thomas M, Michael Soiron, Júlia E E de Oliveira, and Arnaldo de A. Araújo. 2012. "ComputerAided Diagnostics of Screening Mammography Using Content-Based Image Retrieval." Medical Imaging 2012: Computer-Aided Diagnosis. SPIE-Intl Soc Optical Eng.

Do, M N, and M Vetterli. 2005. "The Contourlet Transform: An Efficient Directional Multiresolution Image Representation." IEEE Transactions on Image Processing 14 (12). Institute of Electrical and Electronics Engineers (IEEE): 2091-2106. https://doi.org/10.1109/tip.2005.859376.

Donahue, Jeff, Yangqing Jia, Oriol Vinyals, Judy Hoffman, Ning Zhang, Eric Tzeng, and Trevor Darrell. 2013. “DeCAF: A Deep Convolutional Activation Feature for Generic Visual Recognition,” October. http://arxiv.org/abs/1310.1531.

Dong, Min, Xiangyu Lu, Yide Ma, Yanan Guo, Yurun Ma, and Keju Wang. 2015. “An Efficient Approach for Automated Mass Segmentation and Classification in Mammograms." Journal of Digital Imaging 28 (5). Springer Nature: 613-25. https://doi.org/10.1007/s10278-015-9778-4.

El-Naqa, I, Y Yang, N P Galatsanos, R M Nishikawa, and M N Wernick. 2004. "A Similarity Learning Approach to Content-Based Image Retrieval: Application to Digital Mammography." IEEE Transactions on Medical Imaging 23 (10). Institute of Electrical and Electronics Engineers (IEEE): 1233-44.

Ganesan, Karthikeyan, U Rajendra Acharya, Chua Kuang Chua, Lim Choo Min, K Thomas Abraham, and Kwan-Hoong Ng. 2013. "Computer-Aided Breast Cancer Detection Using Mammograms: A Review." IEEE Reviews in Biomedical Engineering 6. Institute of Electrical and Electronics Engineers (IEEE): 77-98.

Gedik, Nebi, Ayten Atasoy, and Yusuf Sevim. 2016. "Investigation of Wave Atom Transform by Using the Classification of Mammograms." Applied Soft Computing 43: 546-52.

Hanbay, K., N. Alpaslan, M.F. Talu, D. Hanbay, A. Karci, and A.F. Kocamaz. 2015. “Continuous Rotation Invariant Features for Gradient-Based Texture Classification." Computer Vision and Image Understanding 132. https://doi.org/10.1016/j.cviu.2014.10.004.

Jadoon, M. Mohsin, Qianni Zhang, Ihsan Ul Haq, Sharjeel Butt, and Adeel Jadoon. 2017. “Three-Class Mammogram Classification Based on Descriptive CNN Features." BioMed Research International 2017. Hindawi Publishing Corporation: 1-11.

Jen, Chun-Chu, and Shyr-Shen Yu. 2015. "Automatic Detection of Abnormal Mammograms in Mammographic Images." Expert Systems with Applications 42 (6). Elsevier BV: 3048-55.

Jiao, Zhicheng, Xinbo Gao, Ying Wang, and Jie Li. 2016. "A Deep Feature Based Framework for Breast Masses Classification." Neurocomputing 197. Elsevier BV: 221-31.

Kinoshita, Sérgio Koodi, Paulo Mazzoncini de Azevedo-Marques, Roberto Rodrigues Pereira, Jośe Antônio Heisinger Rodrigues, and Rangaraj Mandayam Rangayyan. 2007. "Content-Based Retrieval of Mammograms Using Visual Features Related to Breast Density Patterns." Journal of Digital Imaging 20 (2). Springer Nature: 172-90.

Krizhevsky, Alex, Ilya Sutskever, and Geoffrey E. Hinton. 2012. "ImageNet Classification with Deep Convolutional Neural Networks." https://papers.nips.cc/paper/4824-imagenet-classification-withdeep-convolutional-neural-networks.

Liu, Xiaoming, and Jinshan Tang. 2014. “Mass Classification in Mammograms Using Selected Geometry and Texture Features, and a New SVM-Based Feature Selection Method." IEEE Systems Journal 8 (3). Institute of Electrical and Electronics Engineers (IEEE): 910-20.

Meselhy Eltoukhy, Mohamed, Ibrahima Faye, and Brahim Belhaouari Samir. 2010. "A Comparison of Wavelet and Curvelet for Breast Cancer Diagnosis in Digital Mammogram." Computers in Biology and Medicine 40 (4). Elsevier BV: 384-91. 
Moura, Daniel C, and Miguel A Guevara López. 2013. “An Evaluation of Image Descriptors Combined with Clinical Data for Breast Cancer Diagnosis." International Journal of Computer Assisted Radiology and Surgery 8 (4). Springer Nature: 561-74.

Mousa, Dana S AL, Claudia Mello-Thoms, Elaine A Ryan, Warwick B Lee, Mariusz W Pietrzyk, Warren M Reed, Robert Heard, et al. 2014. "Mammographic Density and Cancer Detection." Academic Radiology 21 (11). Elsevier BV: 1377-85. http://dx.doi.org/10.1016/j.acra.2014.06.004.

Nelson, Heidi D. 2009. "Screening for Breast Cancer: An Update for the U.S. Preventive Services Task Force." Annals of Internal Medicine 151 (10). American College of Physicians: 727.

Nishikawa, Robert M. 2007. "Current Status and Future Directions of Computer-Aided Diagnosis in Mammography." Computerized Medical Imaging and Graphics 31 (4-5). Elsevier BV: 224-35.

Rangayyan, Rangaraj M, Fábio J Ayres, and J E Leo Desautels. 2007. "A Review of Computer-Aided Diagnosis of Breast Cancer: Toward the Detection of Subtle Signs." Journal of the Franklin Institute 344 (3-4). Elsevier BV: 312-48. https://doi.org/10.1016/j.jfranklin.2006.09.003.

Roth, Holger R., Le Lu, Jiamin Liu, Jianhua Yao, Ari Seff, Kevin Cherry, Lauren Kim, and Ronald M. Summers. 2016. "Improving Computer-Aided Detection Using Convolutional Neural Networks and Random View Aggregation." IEEE Transactions on Medical Imaging 35 (5): 1170-81. https://doi.org/10.1109/TMI.2015.2482920.

Rouhi, Rahimeh, Mehdi Jafari, Shohreh Kasaei, and Peiman Keshavarzian. 2015. "Benign and Malignant Breast Tumors Classification Based on Region Growing and CNN Segmentation." Expert Systems with Applications 42 (3). Elsevier BV: 990-1002.

Siegel, Rebecca L, Kimberly D Miller, and Ahmedin Jemal. 2015. "Cancer Statistics, 2015." CA: A Cancer Journal for Clinicians 65 (1). American Cancer Society: 5-29. http://dx.doi.org/10.3322/caac.21254.

Sun, Wenqing, Tzu-Liang (Bill) Tseng, Jianying Zhang, and Wei Qian. 2017. "Enhancing Deep Convolutional Neural Network Scheme for Breast Cancer Diagnosis with Unlabeled Data." Computerized Medical Imaging and Graphics 57 (April). Pergamon: 4-9.

Swiderski, Bartosz, Stanislaw Osowski, Jaroslaw Kurek, Michal Kruk, Iwona Lugowska, Piotr Rutkowski, and Walid Barhoumi. 2017. "Novel Methods of Image Description and Ensemble of Classifiers in Application to Mammogram Analysis." Expert Systems with Applications 81: 67-78.

Tabár, László, Bedrich Vitak, Tony Hsiu-Hsi Chen, Amy Ming-Fang Yen, Anders Cohen, Tibor Tot, Sherry Yueh-Hsia Chiu, et al. 2011. "Swedish Two-County Trial: Impact of Mammographic Screening on Breast Cancer Mortality during 3 Decades." Radiology 260 (3). Radiological Society of North America (RSNA): 658-63. http://dx.doi.org/10.1148/radiol.11110469.

Vedaldi, Andrea, and Brian Fulkerson. 2010. "Vlfeat: An Open and Portable Library of Computer Vision Algorithms." In Proceedings of the International Conference on Multimedia - MM '10, 1469. New York, New York, USA: ACM Press. http://dl.acm.org/citation.cfm?doid=1873951.1874249.

Wang, Ying, Jie Li, and Xinbo Gao. 2014. "Latent Feature Mining of Spatial and Marginal Characteristics for Mammographic Mass Classification." Neurocomputing 144. Elsevier BV: 107-18.

Xie, Weiying, Yunsong Li, and Yide Ma. 2016. "Breast Mass Classification in Digital Mammography Based on Extreme Learning Machine." Neurocomputing 173. Elsevier BV: 930-41.

Zhang, Wenlu, Rongjian Li, Houtao Deng, Li Wang, Weili Lin, Shuiwang Ji, Dinggang Shen, et al. 2013. "Mitosis Detection in Breast Cancer Histology Images with Deep Neural Networks." Nature 35 (11). Institute of Electrical and Electronics Engineers (IEEE): 529-33.

- - - 2015. “Deep Convolutional Neural Networks for Multi-Modality Isointense Infant Brain Image Segmentation." NeuroImage 108 (March). Academic Press: 214-24.

Zhang, Yu, Noriko Tomuro, Jacob Furst, and Daniela Stan Raicu. 2011. "Building an Ensemble System for Diagnosing Masses in Mammograms." International Journal of Computer Assisted Radiology and Surgery 7 (2). Springer Nature: 323-29.

Zheng, Bin. 2009. "Computer-Aided Diagnosis in Mammography Using Content-Based Image Retrieval Approaches: Current Status and Future Perspectives." Algorithms 2 (2). MDPI AG: 828-49. 